\title{
Validity of the International HIV Dementia Scale in Brazil
}

\author{
Validade da Escala Internacional de Demência pelo HIV no Brasil \\ Roiza Almeida Rodrigues ${ }^{1}$, Raquel Lisboa Oliveira², Beatriz Grinsztejn³, Marcus Tulius T. Silva ${ }^{4}$
}

\begin{abstract}
HIV-associated neurocognitive disorders (HAND) remain prevalent in highly active antiretroviral therapy (HAART) era. Tests to detect HAND are needed for early diagnosis and treatment. Validity of International HIV Dementia Scale (IHDS) has been determined in different countries. The aims of this study were validate IHDS in a Brazilian cohort of HIV-patients and verify if IHDS can be reliably administered by a nonclinician health professional. One hundred and eighty-seven (187) patients were submitted to a full neuropsychological assessment. IHDS was administered twice to each patient (by a non-clinician and by a neurologist). HAND was diagnosed in 98 individuals (68 on HAART). IHDS had sensitivity of $55 \%$ and specificity of $80 \%$. IHDS had fair agreement with neuropsychological tests (k 0.355) and moderate-to-strong agreement between different evaluators (interclass correlation coefficient (ICC) 0.684). HAND is prevalent nowadays. IHDS is quick and easy to administer, but has marginal sensitivity for the detection of HIV cognitive impairment other than dementia.
\end{abstract}

Key words: Acquired Immunodeficiency Syndrome, HIV, dementia.

\section{RESUMO}

Distúrbios neurocognitivos associados ao HIV (HAND) ainda são comuns em pacientes usando terapia antirretroviral de alta eficácia (HAART). Testes diagnósticos para detecção de HAND são necessários para diagnóstico e terapia precoces. Nossos objetivos foram validar em uma população brasileira a escala internacional de demência pelo HIV (IHDS), já utilizada em outros países, e avaliar se pode ser confiavelmente aplicada por um profissional não médico. Avaliamos 187 pacientes com uma extensa bateria neuropsicológica. IHDS foi ministrada duas vezes (por médico e não médico). HAND foi diagnosticada em 98 indivíduos (68 em uso de HAART). A IHDS teve sensibilidade de 55\% e especificidade de $80 \%$, com pouca concordância com os testes neuropsicológicos ( $k 0,355)$ e moderada a forte concordância entre observadores (coeficiente de correlação interclasse (ICC) 0,684). HAND ainda é prevalente nos dias atuais. IHDS é um instrumento rápido e fácil de ser aplicado, mas com baixa sensibilidade para detecção de déficit cognitivo outro que não demência.

Palavras-Chave: Síndrome de Imunodeficiência Adquirida, HIV, demência.

The International HIV Dementia Scale (IHDS) is a crosscultural screening test to detect HIV dementia. It is quick and does not require a neurologist to administer it. It was initially tested on HIV patients from the USA and Uganda, with reported sensitivity and specificity of 80 and $55 \%$, respectively ${ }^{1}$. Subsequently, it was translated into different languages and validated in distinct settings ${ }^{2,3}$. We aimed to validate the IHDS in a Brazilian cohort of HIV patients and determine if non-clinician health professionals can reliably administer the IHDS.

\section{METHODS}

We randomly selected 187 of 2,678 HIV patients to undergo a full neurological and neuropsychological assessment. The required number of patients was determined with the statistical program R. Exclusion criteria were age $<18$ years, current or past opportunistic central nervous system disease, current or past history of drug use or alcohol abuse and severe medical, psychiatric or neurologic disorder believed to

${ }^{1} \mathrm{MD}, \mathrm{MSc}$, Neurologist, Clinical Research Laboratory on Neuroinfection Diseases, Evandro Chagas Clinical Research Institute (IPEC), Fundação Oswaldo Cruz (FIOCRUZ), Rio de Janeiro RJ, Brazil;

${ }^{2}$ BPh, MSc, Physiotherapist, IPEC-FIOCRUZ, Rio de Janeiro RJ, Brazil;

${ }^{3} \mathrm{MD}$, PhD, Head, Clinical Research Laboratory on STD/AIDS, IPEC-FIOCRUZ, Rio de Janeiro RJ, Brazil;

${ }^{4} \mathrm{MD}$, PhD, Associated Researcher, Clinical Research Laboratory on Neuroinfection Diseases, IPEC/FIOCRUZ, Rio de Janeiro RJ, Brazil.

Correspondence: Marcus Tulius T. Silva;Avenida Brasil 4365;21040-360 Rio de Janeiro RJ - Brasil; E-mail: marcustulius@ipec.fiocruz.br

Support: Conselho Nacional de Desenvolvimento Científico e Tecnológico (CNPq).

Conflict of interest: There is no conflict of interest to declare.

Received 17 October 2012; Received in final form 12 November 2012; Accepted 19 November 2012. 
be able to interfere with the study evaluations. Data on antiretroviral therapy use, CD4 counts and HIV viral load were retrieved from medical files. A specific diagnostic form was used for neurological assessment ${ }^{4}$.

After translation and back-translation, the IHDS was administered according to the seminal paper ${ }^{1}$. For our Portuguese version, we chose the words cadeira, sapato, tijolo and biscoito to replace the original English words. For semantic clues, we used móvel (cadeira), calçado (sapato), material de construção (tijolo) and alimento (biscoito). The IHDS was administered twice for each patient, first by a physiotherapist (RL) and then by a neurologist (MTTS or RAR). The interval between each assessment was 0-14 days. To avoid word repetition, the physiotherapist provided different words for the patients to recall (vermelho, chapéu, cachorro and feijão). The maximum IHDS score is 12 , and patients with a score $\leq 10$ are considered at risk for HIV dementia ${ }^{1}$.

A neuropsychological test battery was administered to all participants after the IHDS and neurological examination. The battery comprised tests to assess specific domains of neurocognitive function such as verbal memory and learning (Rey Auditory Verbal Learning test), psychomotor performance (Digit Symbol test, Trail Making test), motor speed (Grooved Pegboard test), and frontal systems performance (categorical verbal fluency). Each test was adjusted for age and education using a control group $(n=120)$. Patients were then classified as having normal functioning, asymptomatic neurocognitive impairment (ANI), mild cognitive impairment (MCI) and HIV dementia, according to the proposed criteria for HIV-associated neurocognitive disorders
(HAND) 5 . For statistical analysis, patients with ANI were combined with those with MCI.

SPSS was used for statistical analysis. The following tests were employed: Cronbach's alpha coefficient of reliability, Spearman correlation test, kappa test for inter-rater agreement, Mann-Whitney test, Fisher test, chi-square $\left(\chi^{2}\right)$ test, Youden index $[\mathrm{Y}=$ sensitivity + specificity -1$]$, receiver operating characteristic (ROC) curve and interclass correlation coefficient (ICC). IHDS scores measured by different evaluators (physiotherapist versus neurologist) were compared for each patient. Similarly, the IHDS performance of each patient was matched with his or her neuropsychological diagnosis from a full neuropsychological evaluation.

\section{RESULTS}

The subjects' demographic characteristics are listed in Table. Patients on HAART tended to be older and less educated than HAART-naïve patients $(\mathrm{p}<0.0001)$ and less educated than the negative controls $(p<0.0001)$. HAART-naïve patients were younger than the negative controls $(\mathrm{p}<0.0001)$.

Using the HAND criteria ${ }^{5}$, 98 of 187 individuals (68 on HAART; 30 HAART-naïve) were diagnosed with some cognitive impairment $\left(\chi^{2}\right.$ 9.888, $\left.\mathrm{p}=0.002\right)$. HIV dementia was diagnosed in 28 patients $\left(\chi^{2} 1.961, \mathrm{p}=0.161 ; 19\right.$ on HAART and 9 HAART-naïve $)$ and ANI/MCI in $70\left(\chi^{2} 4.84, \mathrm{p}=0.028\right.$; 49 on HAART and 21 HAART-naïve).

The IHDS had HAND-detection sensitivity and specificity of 55 and $80 \%$, respectively (cut-off $\leq 10$; area under the curve (AUC) 0.731) (Figure). If a cut-off $\leq 11$ was used, the sensitivity

Table. Demographic characteristics and neuropsychological results of HIV-infected patients and HIV-negative controls.

\begin{tabular}{|c|c|c|c|c|}
\hline & HAART naïve & HAART & HIV-negative & p-value \\
\hline Age & $32.5(19-69)$ & $44(20-73)$ & $41.5(3077)$ & $<0.001$ \\
\hline Education & $11(321)$ & $7(1-18)$ & $11(1-25)$ & $<0.001$ \\
\hline Female & $27(37.5 \%)$ & $60(52.2 \%)$ & $69(57.5 \%)$ & - \\
\hline CD4 count & $575.5(34-1610)$ & $392.5(7-1356)$ & NA & $<0.001$ \\
\hline IHDS 1 & $11(6.5-12)$ & $10.5(3-12)$ & NA & 0.002 \\
\hline IHDS 2 & $11(5.5-12)$ & $10.5(3-12)$ & NA & 0.005 \\
\hline DS & $35(0-64)$ & $25(4-60)$ & $47.5(14-72)$ & $<0.001$ \\
\hline TRAILA & $36(16-166)$ & 50.5 (12-203) & $43(24-120)$ & $<0.001$ \\
\hline TRAIL B & $95(31-220)$ & $112(34-290)$ & $89(34-232)$ & 0.041 \\
\hline Verbal fluency & $19(4-40)$ & $16(7-34)$ & $19(9-32)$ & 0.012 \\
\hline GPDH & $70(50-290)$ & $77(10-235)$ & $68(55-123)$ & 0.006 \\
\hline GPNDH & $76(55-295)$ & $85(56-305)$ & $76(62-141)$ & 0.003 \\
\hline RAVLT1 & $5(1-8)$ & $4(1-8)$ & $6(1-12)$ & $<0.001$ \\
\hline RAVLT5 & $12(2-15)$ & $10(4-15)$ & $12(7-15)$ & 0.005 \\
\hline REV1 & $9(2-15)$ & $8(0-15)$ & $10(2-15)$ & 0.004 \\
\hline REV2 & $9(2-15)$ & $8(0-15)$ & $10(4-15)$ & 0.004 \\
\hline
\end{tabular}

NA: not applicable; HAART: highly active antiretroviral therapy; IHDS 1: International HIV dementia scale applied by clinician; IHDS 2: International HIV dementia scale applied by physiotherapist;DS: digit symbol;TRAILA and TRAIL B: trail making test part A and B;GPDH: grooved pegboard with dominant hand; GPNDH: grooved pegboard with non-dominant hand; RAVLT1: Rey auditory verbal learning test first trial; RAVLT5: Rey auditory verbal learning test last trial; REV 1 and REV 2: Rey auditory verbal learning test first and second evocation, respectively. All results shown are median (range), except Female, which is absolute number (percentage). 


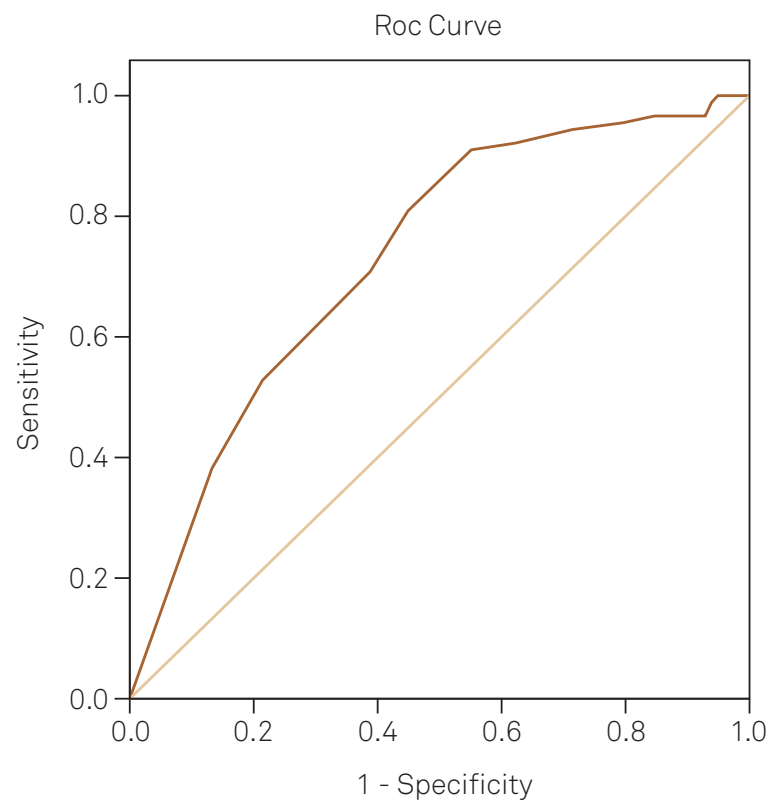

IHDS:International HIV dementia scale; HAND:HIV-associated neurocognitive disorders. $A \cup C=0.731$; Standard error $(S E)=0.037 ; 95 \% \mathrm{Cl} 0.660-0.803$. Figure. Receiver operating characteristic of the International HIV Dementia Scale (cut-off $\leq 10)$ compared to neuropsychological assessment (normal versus HIVassociated neurocognitive disorders).

and specificity for diagnosing HAND changed to 78 and $52 \%$, respectively. An additional analysis excluding ANI/MCI cases and using a cut-off $\leq 10$ was performed, and the sensitivity and specificity increased to 78.5 and $80.8 \%$, respectively. If all HIV dementia cases were excluded, the sensitivity of IHDS decreased to $45.7 \%$ (cut-off $\leq 10$ ). However, with a cutoff $\leq 11$, the sensitivity and specificity for detecting ANI/MCI increased to 75.7 and $52.8 \%$, respectively. Considering only ANI/MCI cases, the Youden index for cut-offs of 10 and 11 was 0.265 and 0.285 , respectively.

IHDS had fair agreement ${ }^{6}$ with neuropsychological tests (kappa=0.355; 95\%CI 0.342-0.369), and moderate-to-strong agreement between different evaluators (clinician and non-clinician; ICC 0.684, 95\%CI 0.519-0.793).

\section{DISCUSSION}

This is the first study to evaluate IHDS performance in a Brazilian cohort of HIV patients. The occurrence and prevalence of HAND is neglected in Brazil, making studies in this field relevant. The prevalence of HAND was 52.4\%: 28 patients with HIV dementia (28.5\%) and 70 patients with ANI/ MCI (71.4\%). Patients on HAART were more likely to have HAND than HAART-naïve patients were $\left(\chi^{2} 5.14 ; \mathrm{p}=0.020\right)$. This may be because patients on HAART have been infected for a longer period and have lower nadir CD4 counts (data not shown). Our data are in accordance with those of others, demonstrating that a history of a low-nadir CD4 count is a strong predictor of neurocognitive impairment ${ }^{7}$.

A screening test for early recognition of HAND has clinical and research relevance. The ideal tool would be quick and easy to use and applicable to different settings. The IHDS is a very brief and easy-to-perform test intended to detect HIV dementia ${ }^{1}$. In our cohort, the IHDS had a sensitivity and specificity for diagnosing HIV dementia of 78.5 and $80.8 \%$, respectively. However, the sensitivity decreased to $45.7 \%$ for diagnosing ANI and MCI. IHDS sensitivity could be improved by increasing the IHDS cut-off score to 11 . When we used a cutoff $\leq 11$, the sensitivity and specificity for detecting ANI/MCI was 75.7 and $52.8 \%$, respectively. The Youden index was higher when we used the cut-off of $\leq 11$ instead of 10 (0.285 versus 0.265). The Youden index is a frequently used summary measure of the ROC curve, measuring the effectiveness of a diagnostic marker and enabling the selection of an optimal threshold value for the marker ${ }^{8}$. The index ranges from -1 to +1 . A result closer to +1 suggests an ideal cut-off value. We believe that patients with a score $\leq 11$ should undergo a full neuropsychological assessment. This is important because ANI and MCI are risk factors for developing HIV dementia, and HAND is associated with poor adherence to HAART and higher morbidity and mortality ${ }^{9}$. In addition, early detection of ANI/MCI in HAART-naïve patients could help guide the initiation of HAART.

Finally, we demonstrated that a non-clinician health professional could administer the IHDS with moderate-to-strong agreement between different evaluators (ICC 0.684). IHDS could be useful prior to a clinical appointment and during follow-up for detection of cognitive decline necessitating specialist referral.

In conclusion, HAND remains prevalent (52.4\%) in HIV patients, and its early recognition is essential. At a cut-off score of $\leq 11$, the IHDS had sensitivity of $75.7 \%$ and specificity of $52.8 \%$ for detecting subtle forms of HAND other than HIV dementia. Additionally, we found that the IHDS could be reliably administered by non-clinician medical professionals.

\section{References}

1. Sacktor NC, Wong M, Nakasujja N, et al. The International HIV Dementia Scale: a new rapid screening test for HIV dementia. AIDS (London, England) 2005;19:1367-1374.

2. Njamnshi AK, Djientcheu Vde P, Fonsah JY, Yepnjio FN, Njamnshi DM, Muna WE. The International HIV Dementia Scale is a useful screening tool for HIV-associated dementia/cognitive impairment in HIV-infected adults in Yaounde-Cameroon. AIDS 2008;49:393-397.

3. Wojna V, Skolasky RL, McArthur JC, et al. Spanish validation of the HIV dementia scale in women. AIDS Patient Care STDs 2007;21:930-941. 
4. Nomenclature and research case definitions for neurologic manifestations of human immunodeficiency virus-type 1 (HIV-1) infection. Report of a Working Group of the American Academy of Neurology AIDS Task Force. Neurology 1991;41:778-785.

5. Antinori A, Arendt G, Becker JT, et al. Updated research nosology for HIVassociated neurocognitive disorders. Neurology 2007;69:1789-1799.

6. Landis JR, Koch GG. An application of hierarchical kappa-type statistics in the assessment of majority agreement among multiple observers. Biometrics 1977;33:363-374.
7. Heaton RK, Clifford DB, Franklin DR, Jr., et al. HIV associated neurocognitive disorders persist in the era of potent antiretroviral therapy: CHARTER Study. Neurology 2010;75:2087-2096.

8. Fluss R, Faraggi D, Reiser B. Estimation of the Youden Index and its associated cutoff point. Biometr J 2005;47:458-472.

9. Herlihy D, Samarawickrama A, Gibson S, Taylor C, O'Flynn D. HIV-associated neurocognitive disorder: rate of referral for neurorehabilitation and psychiatric comorbidity. Internat J STD AIDS 2012;23:285-286. 